Article

\title{
Financial Compass for Slovak Enterprises: Modeling Economic Stability of Agricultural Entities
}

\author{
Katarina Valaskova ${ }^{1, *(\mathbb{D})}$, Pavol Durana ${ }^{1} \mathbb{D}$, Peter Adamko ${ }^{1}$ and Jaroslav Jaros ${ }^{2}$ \\ 1 Faculty of Operation and Economics of Transport and Communications, University of Zilina, Univerzitna 1, \\ 01026 Zilina, Slovakia; pavol.durana@fpedas.uniza.sk (P.D.); peter.adamko@fpedas.uniza.sk (P.A.) \\ 2 Center for Technology Transfer, University of Zilina, University Science Park, Univerzitna 1, \\ 01026 Zilina, Slovakia; jaroslav.jaros@uvp.uniza.sk \\ * Correspondence: katarina.valaskova@fpedas.uniza.sk
}

Received: 10 April 2020; Accepted: 6 May 2020; Published: 7 May 2020

\begin{abstract}
The risk of corporate financial distress negatively affects the operation of the enterprise itself and can change the financial performance of all other partners that come into close or wider contact. To identify these risks, business entities use early warning systems, prediction models, which help identify the level of corporate financial health. Despite the fact that the relevant financial analyses and financial health predictions are crucial to mitigate or eliminate the potential risks of bankruptcy, the modeling of financial health in emerging countries is mostly based on models which were developed in different economic sectors and countries. However, several prediction models have been introduced in emerging countries (also in Slovakia) in the last few years. Thus, the main purpose of the paper is to verify the predictive ability of the bankruptcy models formed in conditions of the Slovak economy in the sector of agriculture. To compare their predictive accuracy the confusion matrix (cross tables) and the receiver operating characteristic curve are used, which allow more detailed analysis than the mere proportion of correct classifications (predictive accuracy). The results indicate that the models developed in the specific economic sector highly outperform the prediction ability of other models either developed in the same country or abroad, usage of which is then questionable considering the issue of prediction accuracy. The research findings confirm that the highest predictive ability of the bankruptcy prediction models is achieved provided that they are used in the same economic conditions and industrial sector in which they were primarily developed.
\end{abstract}

Keywords: modeling in economic; economic sustainability; prediction models; financial distress; market risk; agriculture

\section{Introduction}

Financial stability and a healthy financial situation are very important aspects of enterprise assessment by potential creditors and business partners. Analyzing the past results is not the only important measure, each enterprise should also look at its future direction, which led to the development of prediction models. The main importance of these methods is to estimate the future potential of an enterprise in order to correctly set its real financial objectives (Rahman et al. 2017).

The question of corporate financial distress and bankruptcy prediction has been the most discussed problems of economists around the world in recent decades (Delina and Packova 2013). According to Barbuta-Misu and Madaleno (2020), bankruptcy prediction is a very real issue worldwide both in academic research and practice. Durica et al. (2019) claim that the problem of bankruptcy forecasting is a topical issue, especially in times of strong market competition and business crises. They affirm that if an enterprise wants to thrive and successfully operate in a market environment, it should conduct a regular financial analysis of its activities, evaluate its successes and failures, and use the results to make 
strategic decisions about future business development. In order to predict the financial reliability of enterprises, there is a need to follow the development of crucial financial ratios. As investigated in the study of Kliestik et al. (2020) and Kovacova et al. (2019), recognition of key financial indicators enables modeling of the probability of failure and prediction of financial difficulties at a specific accuracy level. Virag (2004) proves that the choice of ratios in the process of prediction modeling is restricted strongly by the fantasy of the analyst and the number of items in the financial statement.

Despite the large number of existing bankruptcy prediction models that have been developed worldwide using different statistical methods to achieve the best prediction accuracy, the prediction of bankruptcy risk is still challenging. The reason is that the prediction models have the most significant predictive ability provided that they are formed in specific national environment and exact sector of the economy (Kovacova and Kliestik 2017; Krastev et al. 2019). Thus, the purpose of the paper is to analyze the bankruptcy prediction models, which were developed in the environment of the Slovak economy in the agricultural sector. The choice of the sector is underlined by the fact that after the transformation of the Slovak economy, the first bankruptcy models were developed in this sector (and until now they are the most reputable bankruptcy prediction models of Slovakia). The assessment of the potential risks and the threat of bankruptcy in the agricultural sector plays an important role from economic, social, ethno-cultural, and environmental perspectives. Dadayan et al. (2020) affirm that activities in agriculture are risky, and the growth of production and financial stability depend on how subjects overcome economic risks. As declared by Sedlacek (2010), business entities in the agricultural sector are influenced not only by financial problems but also by many force majeure circumstances, confirming that is more difficult for these companies to transform their activities compared to subjects in other economic sectors. As stated by Dinterman et al. (2018), enterprises in the agricultural sector experience financial stress if they are able to generate cash flow to meet their debt services payments. Patrick et al. (2016) stress that the recent development of the agricultural sector causes lower net income, stagnation of land values and an increase in the volume of debts causing huge problems in the agricultural sector worldwide.

The main aim of the paper is to portray the bankruptcy models which were developed in conditions of the Slovak republic, especially in the sector of agriculture, verify their predictive ability using divergent statistical methods, and explore the importance of financial ratios in the prediction of financial stability. Its originality lies in the fact that it is the pioneering study analyzing all models for agricultural enterprises developed in the same economic environment. The first models formed in the specific Slovak environment, were the multiple discriminant analysis (MDA) models of Chrastinova (1998) and Gurcik (2002) focused on the assessment of enterprises in the agricultural sector, which used to be the key industry of the country. However, since that time, the researchers and academicians have been mostly focused on the development of predictions models for the Slovak market, without specific orientation on the industry. Kliestik et al. (2018a) published a detailed analysis of prediction models developed and used in transition economies and they formed several models for Slovak environment, which are also included in the sample of analyzed models. The research problem includes the application of several statistical methods, contingency tables, confusion matrix, and receiver operating characteristic curve (ROC) to compare the accuracy of the prediction models. Comparison of several models being developed in the same economic conditions helps judge not only the correctness of individual models, but also the effect of financial ratios used for prediction. The research confirms that those models which are proposed for the agricultural sector highly outperform other models considering their prediction accuracy and refuses the use of models which were not developed in similar economic conditions.

The paper is divided into four main parts. The literature review highlights the most important and the most relevant studies and researches being published in Slovak conditions and worldwide in the field of bankruptcy modeling. Materials and Method addresses a description of prediction models entering the analysis, portrays statistical methods and tests used, introduces the database of enterprises, and delineates the methodological steps of the research. Results and Discussion summarizes the 
important findings, presents the results of the comparison of prediction models, and compares them with other relevant studies.

\section{Literature Review}

The origins and literary sources of predictive bankruptcy models date back to 1930, starting with studies on using ratio analysis to predict future bankruptcy. Until the mid-1960s, research focused only on one-factor analysis. The one-factor study by Beaver (1966) is generally the most widespread and most recognized. In 1968, Altman published the first multi-factor study, which is still very popular today. From Beaver (1966) and Altman (1968), hundreds of models have been developed both in specific national conditions and different economic groupings.

As portrayed in the study of Kliestik et al. (2018b), it is extremely important to predict bankruptcy risk as corporations have become more global and more complex. Jiang et al. (2018) stress that the ability to predict the occurrence of extreme changes is significant also in financial risk management. Moreover, company management needs to ensure that the conditions of financial distress do not develop into a bankruptcy by identifying the financial ratios which have a major impact on the financial conditions of enterprises (Mahtani and Garg 2018). Managing insolvency and failure help strengthen the market competitiveness and growth (Eklund et al. 2020; Krastev et al. 2019), form more efficient strategies when modeling financial stability (Popescu and Victor 2018; Ludbrook et al. 2019), and improve the recovery rate of stakeholders (Sautner and Vladimirov 2018). The importance of financial health modeling is confirmed in the research of Prusak (2019) who assesses and reviews the level of advancement of bankruptcy prediction research in the eastern European countries. There are several different statistical methods which can be used when developing bankruptcy prediction models, which are distinguished by the level of prediction accuracy achieved. Ben Jabeur and Fahmi (2018) and Garcia et al. (2019) compare the most frequently used statistical methods of financial distress modeling (discriminant analysis, logistic regression, and random forest) to verify their prediction accuracy. Their results unveil that the random forest method allows better accuracy and minimizes type I and type II errors which correspondents with the finding of Durica et al. (2019). Despite the fact, that the researches of many authors claim, e.g., Naidu and Govinda (2018); Le et al. (2018) or Hosaka (2019), that the machine learning models are much better when predicting the corporate bankruptcy, there are also several studies, e.g., Barboza et al. (2017), which affirm that machine learning models achieve only $10 \%$ better accuracy compared to traditional methods (multiple discriminant analysis and logistic regression). The scientific importance of the MDA method is intensified by the fact that also the first models, and still the most important, are based on this method. Considering the fact that this method takes into account the whole set of common characteristics of the analyzed enterprises as well as their mutual interactions (Siekelova Anna and Adamko 2018), makes the MDA analysis the most preferred method of bankruptcy prediction. Hajek (2018) affirms that systems for predicting corporate rating have attracted significant interest in soft computing research, as these models achieve good results in both accuracy and interpretability.

Nonetheless, not only the statistical methods do play an important role, but there are also perpetual discussions if accounting of market-based information should be used when predicting corporate default (Farooq and Qamar 2019). The research of Li and Faff (2019) reports that relevance of accounting-based information is crucial for enterprises with high information asymmetry while the market-based should be preferred during the financial recession periods (Stefko et al. 2019; Krastev et al. 2020). The empirical findings of Binh et al. (2018) prove that both accounting and market factor, accompanied by changes in the macroeconomic factors, affect the financial distress of enterprises. They underline the importance of the development of prediction models, which includes accounting and macroeconomic indicators (rather than market-based with macroeconomic factors), to achieve high predictive accuracy. The important role of financial ratios in predicting financial distress is explored in the study of Waqas and Md-Rus (2018), whose inclusion of profitability, liquidity, leverage, and cash flow ratios improved the accuracy rate of financial distress modeling using a logit model. 
Inam et al. (2019) confirm that profitability and leverage indicators are the best financial discriminants to predict the financial distress which was proved analyzing the Pakistani firms of the non-financial sector. Another important aspect is presented in the study of Korol (2019) who investigated the effectiveness of bankruptcy prediction models in short- and long-term horizons.

Developing the models for bankruptcy prediction is Slovakia, authors use various statistical methods. Alaka et al. (2018) contribute to a clear understanding of the feature of the tools used to develop bankruptcy prediction models. A closer view of the frequently used statistical methods, analyzing their advantages and disadvantages in term of data requirements are discussed by Svabova and Durica (2019). The first models introduced by Chrastinova (1998) and Gurcik (2002) are based on the principles of the MDA method in the agriculture sector. However, many other models are formed using logistic regression due to more accurate results (Hurtosova 2009; Gulka 2016; Delina and Packova 2013; Harumova and Janisova 2014). Mihalovic (2016) in his study points out that the models based on a logit function outperform the classification ability of the discriminant models. The successful use of logit and probit models is highlighted in the paper of Kovacova and Kliestik (2017), who use these methods to estimate the financial health of Slovak enterprises. The outstanding classification accuracy of the logistic regression model was the main reason why this model was selected for the comparison with learning algorithms in the Slovak conditions. Horvathova and Mokrisova (2018) applied Altman's model and DEA method to search the most appropriate method to measure the financial health, performance, and competitiveness of enterprises operating in tourism. The latest research of Zoricak et al. (2020) provides a complex analysis of the financial predictors and identifies those methods which are the most appropriate to bankruptcy prediction. They reveal that the highest prediction performance is achieved using the geometric mean score validating the model on the database of manufacturing and construction industries-the significant industries of any developed economy.

\section{Materials and Methods}

The verification of the prediction ability of selected Slovak models and the identification of the crucial financial ratios in a specific industry is based on a dataset of Slovak enterprises operating in the agricultural sector (NACE A-Agriculture, forestry, and fishing). Stehel et al. (2019) point out, that one of the basic principles of sustainable agriculture is forecasting its future development. The information about the financial performance of the enterprises was acquired from the Amadeus database provided by the Bureau van Dijk. The final dataset is formed of 3329 enterprises from the NACE A sector, with the financial reports of the last three years-2018, 2017, and 2016. The three-year-long period was chosen to analyze the enterprises as a response to a newly adopted legislation (establishing a status of a company in crisis) which came into force in 2016 and determined limit values to judge the corporate financial stability. According to the new Act No. 7/2005 Coll. on bankruptcy and restructuring and Act No. 513/1991 Coll. of the Commercial Code, an enterprise is in a crisis when it is in decline or in a threat of bankruptcy. Companies are at risk of bankruptcy if their equity-to-liability ratio is less than 8 per 100 . Under the transitional provisions, the ratio of 8 to 100 is only used in 2018 and after. In 2016, a critical value is assumed to be 4 to 100 and in 2017-6 to 100. The enterprise is non-prosperous if together with this restriction of the value of the equity-to-liability ratio, their profit after taxes is negative and the ratio of current-assets-to-current-liabilities is less than 1. Moreover, the enterprises which value of assets is lower the value liabilities (negative equity), are also considered non-prosperous.

\subsection{Database Description}

The enterprises may be then categorized into two main groups of prosperous (financially healthy enterprises with no threat of bankruptcy) and non-prosperous (with the risk of bankruptcy). Table 1 portrays the number of prosperous-financially stable and non-prosperous-financially unstable enterprises in each analyzed year. 
Table 1. Number of prosperous and non-prosperous enterprises in each year.

\begin{tabular}{ccc}
\hline Year & Prosperous & Non-Prosperous \\
\hline 2016 & 2861 & 468 \\
2017 & 2858 & 471 \\
2018 & 2872 & 457 \\
\hline
\end{tabular}

Source: processed by authors.

The models applied to assess the financial performance of agricultural enterprises and reveal the risk of bankruptcy use different financial ratios as predictors. The models use together 23 financial-economic ratios, their descriptive statistics-mean, median, standard deviation and coefficient of variance $(\mathrm{CV})$ - are presented in Table 2 . The ratios cover all important perspectives of financial determinants (Lukason and Camacho-Minano 2019)—including ratios of liquidity, profitability, and leverage.

Table 2. Descriptive statistics of financial-economic ratios.

\begin{tabular}{cccccc}
\hline & Financial-Economic Ratios & Mean & Median & Std. dev. & CV \\
\hline$X_{2}$ & Current Assets/Current Liabilities & 9.94 & 1.14 & 299.85 & 30.16 \\
\hline$X_{3}$ & Gross Profit/Total Assets & 0.13 & 0.09 & 0.12 & 1.29 \\
\hline$X_{4}$ & Net Income/equity & -0.95 & 0.07 & 47.71 & -50.06 \\
\hline$X_{5}$ & EBITDA/Sales & 0.37 & 0.2 & 24.41 & 65.92 \\
\hline$X_{7}$ & Net Income/Total Assets & -0.02 & 0.02 & 0.33 & -14.68 \\
\hline$X_{8}$ & Working Capital/Total Assets & 0.08 & 0.09 & 0.14 & 1.78 \\
\hline$X_{9}$ & Operating profit/Total assets & 0.01 & 0.03 & 0.33 & 33.07 \\
\hline$X_{10}$ & (Non-Current + Current Liabilities)/Total Assets & 0.77 & 0.63 & 0.93 & 1.22 \\
\hline$X_{11}$ & Current assets/Total assets & 0.59 & 0.56 & 0.1 & 0.17 \\
\hline$X_{12}$ & Cash and Cash Equivalents/Total Assets & 0.24 & 0.1 & 0.1 & 0.42 \\
\hline$X_{13}$ & Cash flow/Total Assets & 0.09 & 0.09 & 0.12 & 1.28 \\
\hline$X_{14}$ & Cash flow/(Non-current + Current Liabilities) & 0.68 & 0.17 & 17.26 & 25.47 \\
\hline$X_{15}$ & Current Liabilities/Total Assets & 0.64 & 0.46 & 0.91 & 1.42 \\
\hline$X_{16}$ & Current Assets/Sales & 14.05 & 0.81 & 183.96 & 13.1 \\
\hline$X_{18}$ & Inventories/Sales & 1.03 & 0.11 & 20.99 & 20.48 \\
\hline$X_{20}$ & Net income/Sales & -31.71 & 0.02 & 937.75 & -29.58 \\
\hline$X_{21}$ & Non-Current Liabilities/Total Assets & 0.12 & 0.02 & 0.12 & 1.03 \\
\hline$X_{22}$ & Cash and Cash Equivalents/Current Liabilities & 7.66 & 0.22 & 305.79 & 39.95 \\
\hline$X_{24}$ & Working Capital/Sales & -320.73 & 0.12 & 10246.75 & -31.95 \\
\hline$X_{26}$ & (Current Assets-Inventory)/Current Liabilities & 2.95 & 0.8 & 3.56 & 1.21 \\
\hline$X_{27}$ & Return on Assets (Profit Before Tax/Total Assets) & 0.04 & 0.02 & 0.1 & 4.24 \\
\hline$X_{28}$ & Return on Equity (Profit Before Tax/Equity) & 0.1 & 0.09 & 0.19 & 1.93 \\
\hline$X_{30}$ & Equity/(Non-Current + Current Liabilities) $\times 100$ & 0.36 & 0.28 & 0.11 & 0.31 \\
\hline$X_{35}$ & Profit before Tax/Operating Income & 0.06 & 0.04 & 0.12 & 2.06 \\
\hline & & & & \\
\hline & & & & \\
\hline
\end{tabular}

Source: processed by authors.

To simplify the calculations, the authors unify the nomenclature of the financial predictors in all analyzed models.

\subsection{Description of the Analyzed Models}

The individual prediction models, which are applied to verify the prediction ability of the models are the models based on the multiple discriminant analysis. The purpose of the MDA method is to 
formulate one dependent variable as a linear combination of other independent variables. The essence of the MDA analysis lies in the best classification of the assessed company (industry) into the group of financially stable or unstable enterprises (Vrbka et al. 2019).

As mentioned in the literature review, there are several prediction models being developed in Slovakia, but this study is focused on the verification of eight models which were developed either in the same economic conditions of Slovakia or in the same sector-agriculture. For all these models, the $\mathrm{Z}$ score values were calculated for each enterprise in the dataset and for the analyzed years 2016-2018.

The first bankruptcy prediction models developed in Slovakia, are the models of Chrastinova (1998) and Gurcik (2002), which are focused exclusively on agricultural enterprises. Ch-index of Chrastinova used the sample of 1,123 enterprises to form the model and the results claim the practicability of the model to assess the financial health of enterprises. The Ch-index is calculated as (all the variables are explained in Table 2)

$$
C H=0.37 X_{7}+0.25 X_{20}+0.21 X_{14}-0.1 X_{4}-0.07 X_{10}
$$

The calculated value of the Ch-index can then be classified into three groups. If the resulting value is higher than 2.5 an enterprise belongs to the group of prosperous enterprises, so it has a healthy financial situation. A value lower than -5 indicates a non-prosperous business with an unhealthy financial situation, and if the resulting value is in the range of -5 to 2.5 , an enterprise is placed in the neutral zone. However, as the enterprises need to be grouped only to prosperous and non-prosperous the limit value (mean value) -1.25 was used to categorize the enterprises.

G-index of Gurcik, primarily based on 60 Slovak enterprises and 35 financial ratios, uses five financial ratios as predictors when predicting the future financial development of enterprises

$$
G=3.412 X_{9}+2.226 X_{3}+3.277 X_{5}+3.149 X_{13}-2.063 X_{18}
$$

The calculated G-index value can be divided into three groups. If the value is higher than 1.8 the company belongs to the group of prosperous, if the value is lower than -0.6 the enterprise is non-prosperous. An enterprise belongs to the neutral zone if the G-index is in the range of 1.8 to -0.6 . Due to the same reason, the need for two-stage classification, the limit value (mean value) to categorize enterprises to prosperous and non-prosperous is set at the level 0.6.

To identify other prediction models in the agricultural sector, the models presented by Kliestik et al. (2018a) were adopted. The models may be distinguished according to several criteria, although, for the purpose of the analysis the authors selected the model for small enterprises in the agricultural sector, model for medium-sized enterprises and large enterprises in the agricultural sector, the general model for Slovak agricultural enterprises, and the general Slovak model (calculated for all sectors). The last model was chosen to compare the differences in prediction accuracy. Moreover, to confirm the predictive ability, the revised Altman's model (Altman et al. 2014) was also included.

The prediction model for small enterprises in the agricultural sector was calculated based on the sample of 88,252 small enterprises (66,070 prosperous and 22,182 non-prosperous). The enterprises are classified into two groups (prosperous and non-prosperous) based on the value of the calculated $\mathrm{Z}$ score-a positive value represents a non-prosperous enterprise and a negative value an enterprise that is prosperous. The Z-score is calculated as

$$
Z_{S_{N A C E A}}=-1.412-1,512 X_{4}+2.504 X_{10}-0.06 X_{24}+1.256 X_{28}
$$

To form the prediction model for medium-sized enterprises in the agricultural sector, the financial statements of 15,275 medium-sized enterprises (13,160 prosperous and 2115 non-prosperous) were used. The limit value to classify the enterprises into prosperous and non-prosperous was 0 (positive value for non-prosperous, negative for the prosperous ones). Z-score for medium-sized agricultural enterprises is

$$
Z_{M_{N A C E A}}=1.082+5.105 X_{4}-1.742 X_{10}-4.063 X_{28}
$$


The model for the bankruptcy prediction of large enterprises was developed on a sample of 2181 Slovak enterprises (2062 prosperous and 119 non-prosperous). The formula to calculate Z-score is

$$
Z_{L_{N A C E A}}=-0.863-3.72 X_{4}+8.503 X_{9}+1.417 X_{15}+0.617 X_{16}-1.418 X_{24}
$$

As in the previous two models, a positive value of $Z$ score represents a non-prosperous enterprise and a negative value an enterprise that is prosperous.

To develop the general prediction model for Slovak agricultural enterprises, the data of 105,708 enterprises (81,292 prosperous and 24,416 non-prosperous) was used. The model has the following formula

$$
\begin{aligned}
Z_{S R_{N A C E A}=} & -1.179+0.376 \text { region }_{B A}+0.86 \text { small }-0.095 X_{2}-0.003 X_{4}+1.348 X_{8} \\
& +0.397 X_{12}+0.9 X_{15}-0.008 X_{16}+1,569 X_{21}-0.028 X_{24}+0.074 X_{26} \\
& -1.815 X_{27}-0.249 X_{28}-0.805 X_{35}
\end{aligned}
$$

This model consists of financial ratios discussed in Table 1, however, there are also two dummy variables included in the calculation of the bankruptcy prediction. A zero to one scheme has to be applied to define a certain variation or a category of a dummy (qualitative) variable-region where an enterprise operates and its size. Zero is used when the given variation or category does not occur and one demonstrates the opposite situation, i.e., the occurrence of a given variation or category. The positive value of $\mathrm{Z}$ score determines a non-prosperous business entity, the negative value is a sign of corporate prosperity.

The last introduced model is the general model for Slovak enterprises (with no orientation for a specific sector of the economy). The classification for prosperous and non-prosperous enterprises follow the same principle. The value of $\mathrm{Z}$ score is calculated based on the equation

$$
\begin{aligned}
Z_{S R}=-2.255 & +0.548 N A C E_{I}+0.1 N A C E_{N}-0.285 N A C E_{Q}+0.139 \text { region }_{B A} \\
& +0.097 \text { region }_{K E}+0.980 \text { small }+0.326 \text { medium }+0.016 X_{2} \\
& -0.385 X_{4}-6.716 X_{7}+2.244 X_{10}-0.358 X_{11}+0.761 X_{15}+0.011 X_{22} \\
& +5.431 X_{27}+0.1 X_{28}
\end{aligned}
$$

\subsection{Description of the Statistical Methods Assessing the Predictive Ability of Selected Models}

Calculating the Z score in the analyzed period 2016-2018 for all 3329 agricultural enterprises using the determined models enables the further comparison of the models to verify their prediction

\begin{tabular}{|c|c|c|c|}
\hline & & Actual Values & \\
\hline \multirow[b]{2}{*}{ Predicted values } & & Prosperous & Non-prosperous \\
\hline & $\begin{array}{c}\text { Prosperous } \\
\text { Non-prosperous }\end{array}$ & $\begin{array}{c}\text { True positive (TP) } \\
\text { False negative (FN) }\end{array}$ & $\begin{array}{l}\text { False positive (FP) } \\
\text { True negative (TN) }\end{array}$ \\
\hline
\end{tabular}
accuracy. To compare the contingency tables of individual models, confusion matrix, and receiver operating characteristic curve (ROC) were used.

A confusion matrix (Table 3 ) is a technique for summarizing the performance of a classification algorithm. It is a predictive analytics measure, which reports the number of false positive (FP, type I error), false negative (FN, type II error), true positive (TP, sensitivity), and true negative (TN, specificity) cases (Klepac and Hampel 2016).

Table 3. Confusion matrix.

Sensitivity measures the proportion of truly positive cases to the total number of positive cases; it is the percentage of properly classified prosperous enterprises. Specificity is defined as the ratio of correctly identified negative cases to all negative cases in the dataset; it is the percentage of correctly 
classified non-prosperous enterprises. Type II error defines the number of true negative cases which were identified as positive, and vice versa, type I error quantifies the number of true positive cases classified as false negative. The total accuracy of the prediction model is calculated using the equation

$$
\text { total accuracy }=\frac{T P+T N}{T P+F P+F N+T N}
$$

Based on the calculated values of specificity and sensitivity, the ROC curve is portrayed. It is a plot of the true positive rate against the false positive rate for the different possible cutpoints of a diagnostic test. The ROC curve reveals a trade-off between sensitivity and specificity-increasing sensitivity implies decreasing specificity and vice versa. The biggest benefit of using the ROC curve is that it is independent of the change in the proportion of outcomes.

The predictive accuracy is measured by the area under the curve (AUC). An area of 1 represents a perfect test; an area of 0.5 represents a worthless test. Five different levels of accuracy are distinguished: (i) excellent when the AUC value is in the range $\langle 0.9 ; 1\rangle$; (ii) good $\langle 0.8 ; 0.9$ ); (iii) fair $\langle 0.7 ; 0.8$ ); (iv) poor $\langle 0.6 ; 0.7)$. If the value of the AUC is less than 0.6 , the model is not appropriate to be used for the bankruptcy prediction. Determination of the most accurate prediction models is then used to explore the importance of financial predictors.

\section{Results and Discussion}

The whole dataset of 3329 enterprises was used when calculating the Z score of Ch-index, G-index, Altman model, the general prediction model for Slovak agricultural enterprises and the general model for Slovak enterprises. To model the economic stability of small, medium-sized, and large enterprises, the whole sample was divided according to the size of companies, Table 4 . The prosperity of enterprises is determined based on the legislation principles as depicted earlier in the paper.

Table 4. Number of prosperous and non-prosperous enterprises in each year.

\begin{tabular}{ccccccc}
\hline & \multicolumn{5}{c}{ Categorization of Enterprises } \\
\cline { 2 - 6 } Year & \multicolumn{2}{c}{ Small } & \multicolumn{2}{c}{ Medium-Sized } & \multicolumn{2}{c}{ Large } \\
\cline { 2 - 7 } & Prosperous & Non-Prosperous & Prosperous & Non-Prosperous & Prosperous & Non-Prosperous \\
\hline 2016 & 1888 & 391 & 941 & 66 & 43 & 0 \\
2017 & 1867 & 412 & 948 & 59 & 43 & 0 \\
2018 & 1866 & 413 & 953 & 54 & 42 & 1 \\
\hline \multicolumn{7}{c}{ Source: processed by authors. }
\end{tabular}

The results of the empirical research and their statistical processing are summarized in Table 5, which portrays the results of the confusion matrix.

Firstly, to judge the prediction accuracy of Ch-index and G-index, their high predictive strength would have been expected. Both models are based on five-factor discriminant analysis, but their predictors differ significantly. However, quantifying their total accuracy, Ch-index achieves much better results, an average value of $86.97 \%$. The ability of the model to classify correctly prosperous enterprises is excellent, more than $90 \%$ in each analyzed year, compared to the low level of identification of non-prosperous enterprises, which is only slightly over $10 \%$. It means that the type II error is dominant, allowing the model to identify true negative cases as positive ones. The three-year average of the total accuracy of G-index is $53.11 \%$. Despite the fact, that this prediction ability is not significant, the model achieves more than $70 \%$ (in each analyzed year) accuracy when identifying the non-prosperous enterprises.

Modeling economic stability of small agricultural enterprises, the results are not very acceptable, as the total accuracy of the model only slightly exceeds $50 \%$. However, the type II error is low and the model succeeds in the identification of the non-prosperous agricultural enterprises. The prediction strength of the model for medium-sized agricultural enterprises is weak, achieving only a level of $40 \%$ of total accuracy, sensitivity, and specificity on average. Nonetheless, the best accuracy is modeled for 
large agricultural enterprises. Total accuracy of the model is very high (three-year average of $80 \%$ ), the percentage of properly classified prosperous enterprises is also more than $78 \%$ on average and the model correctly identified 100\% negative cases to all negative cases in the dataset in 2018 (there were no non-prosperous enterprises in 2016 and 2017).

The general prediction model for Slovak agricultural enterprises has relevant and significant results when assessing total accuracy, which is more than $65 \%$ in each analyzed period. The level of sensitivity also exceeds the limit of $60 \%$ and the value of specificity indicates that more than $87 \%$ of non-prosperous enterprises may be identified by this model.

Table 5. Prediction accuracy of models measured by confusion matrix.

\begin{tabular}{|c|c|c|c|c|c|c|}
\hline \multirow[b]{2}{*}{ Model } & \multirow[b]{2}{*}{ Year } & \multicolumn{5}{|c|}{ Confusion Matrix Parameters } \\
\hline & & $\begin{array}{c}\text { Total } \\
\text { Accuracy }\end{array}$ & Sensitivity & Specificity & Type I Error & Type II Error \\
\hline \multirow{3}{*}{$\mathrm{CH}$-index } & 2018 & $86.54 \%$ & $98.88 \%$ & $11.11 \%$ & $1.12 \%$ & $88.89 \%$ \\
\hline & 2017 & $86.84 \%$ & $99.09 \%$ & $12.53 \%$ & $0.91 \%$ & $87.47 \%$ \\
\hline & 2016 & $87.53 \%$ & $99.27 \%$ & $13.79 \%$ & $0.73 \%$ & $86.21 \%$ \\
\hline \multirow{3}{*}{ G-index } & 2018 & $51.10 \%$ & $47.75 \%$ & $71.58 \%$ & $52.25 \%$ & $28.42 \%$ \\
\hline & 2017 & $53.20 \%$ & $50.00 \%$ & $72.61 \%$ & $50.00 \%$ & $27.39 \%$ \\
\hline & 2016 & $55.03 \%$ & $52.23 \%$ & $72.65 \%$ & $47.77 \%$ & $27.35 \%$ \\
\hline \multirow{3}{*}{ Altman model } & 2018 & $13.55 \%$ & $0.07 \%$ & $95.94 \%$ & $99.93 \%$ & $4.06 \%$ \\
\hline & 2017 & $13.76 \%$ & $0.24 \%$ & $95.75 \%$ & $99.76 \%$ & $4.25 \%$ \\
\hline & 2016 & $13.46 \%$ & $0.24 \%$ & $96.50 \%$ & $99.76 \%$ & $3.50 \%$ \\
\hline \multirow{3}{*}{ General model of SR } & 2018 & $41.48 \%$ & $32.33 \%$ & $97.44 \%$ & $67.67 \%$ & $2.56 \%$ \\
\hline & 2017 & $41.15 \%$ & $32.19 \%$ & $95.54 \%$ & $67.81 \%$ & $4.46 \%$ \\
\hline & 2016 & $41.57 \%$ & $32.80 \%$ & $96.72 \%$ & $67.20 \%$ & $3.28 \%$ \\
\hline \multirow{3}{*}{$\begin{array}{l}\text { General agricultural } \\
\text { model of SR }\end{array}$} & 2018 & $64.82 \%$ & $61.03 \%$ & $88.03 \%$ & $38.97 \%$ & $11.97 \%$ \\
\hline & 2017 & $65.18 \%$ & $61.20 \%$ & $89.38 \%$ & $38.30 \%$ & $10.62 \%$ \\
\hline & 2016 & $67.35 \%$ & $64.10 \%$ & $87.75 \%$ & $35.90 \%$ & $12.25 \%$ \\
\hline \multirow{3}{*}{$\begin{array}{l}\text { Agricultural model for } \\
\text { small enterprises }\end{array}$} & 2018 & $57.53 \%$ & $51.66 \%$ & $84.02 \%$ & $48.34 \%$ & $15.98 \%$ \\
\hline & 2017 & $54.67 \%$ & $49.12 \%$ & $79.85 \%$ & $50.88 \%$ & $20.15 \%$ \\
\hline & 2016 & $54.98 \%$ & $50.16 \%$ & $78.26 \%$ & $49.84 \%$ & $21.74 \%$ \\
\hline \multirow{3}{*}{$\begin{array}{l}\text { Agricultural model for } \\
\text { medium-sized } \\
\text { enterprises }\end{array}$} & 2018 & $39.82 \%$ & $40.40 \%$ & $29.63 \%$ & $59.60 \%$ & $70.37 \%$ \\
\hline & 2017 & $38.73 \%$ & $39.35 \%$ & $28.81 \%$ & $60.65 \%$ & $71.19 \%$ \\
\hline & 2016 & $41.11 \%$ & $40.81 \%$ & $45.45 \%$ & $59.19 \%$ & $54.55 \%$ \\
\hline \multirow{3}{*}{$\begin{array}{l}\text { Agricultural model for } \\
\text { large enterprises }\end{array}$} & 2018 & $79.07 \%$ & $78.57 \%$ & $100.00 \%$ & $21.43 \%$ & $0.00 \%$ \\
\hline & 2017 & $83.72 \%$ & $83.72 \%$ & $0.00 \%$ & $16.28 \%$ & $0.00 \%$ \\
\hline & 2016 & $74.42 \%$ & $74.42 \%$ & $0.00 \%$ & $25.58 \%$ & $0.00 \%$ \\
\hline
\end{tabular}

Source: processed by authors.

The empirical research includes also two models which were not developed in the agricultural sector, though one of them was formed in the Slovak environment. Following the results of the confusion matrix, the prediction ability of the general Slovak model is only about $41 \%$, achieving very good ability ( $96.5 \%$ on average) in the identification of non-prosperous enterprises. Much worse are the results of the Altman's model applied in the Slovak business environment, as the model only achieves good prediction accuracy when identifying non-prosperous entities.

The prediction models are also analyzed using the ROC curves, which shows the tradeoff between sensitivity and specificity. The closer the curve follows the left-hand border and then the top border of the ROC space, the better the accuracy of the model. Table 6 portrays the exact prediction accuracy, which is measured by the area under the curve. 
Table 6. Prediction accuracy of models measured by AUC.

\begin{tabular}{cccccc}
\hline & Year & CH-Index & G-Index & Altman Model & $\begin{array}{c}\text { General Model } \\
\text { of SR }\end{array}$ \\
\hline \multirow{4}{*}{ AUC } & $\mathbf{2 0 1 8}$ & 0.802 & 0.675 & 0.261 & 0.058 \\
& $\mathbf{2 0 1 7}$ & 0.741 & 0.686 & 0.231 & 0.073 \\
& $\mathbf{2 0 1 6}$ & 0.788 & 0.708 & 0.359 & 0.076 \\
\hline \multirow{4}{*}{ AUC } & Year & Agricultural & Model for Small & Agricultural Model & Agricultural \\
& & Model of SR & Enterprises & Enterprises & $\begin{array}{c}\text { Agrium-Sized } \\
\text { Enterprises }\end{array}$ \\
& $\mathbf{2 0 1 8}$ & 0.855 & 0.833 & 0.296 & 0.952 \\
& $\mathbf{2 0 1 7}$ & 0.866 & 0.786 & 0.267 & - \\
\hline
\end{tabular}

Source: processed by authors.

The bankruptcy prediction model has sufficient predictive ability provided that the value of AUC is more than 0.6. The results indicate, that the Altman's model and the general model of Slovakia do not achieve the required limit value, which may be a consequence of the fact, that they do not accept the specific conditions of agricultural sector. However, also the model for medium-sized agricultural enterprises shows unsatisfactory results and it would be better to prefer another model when modeling the financial stability of medium-sized enterprises. The best results are achieved by the model for large agricultural enterprises, although, its accuracy is calculated only for 2018, as in 2017 and 2016 there were no non-prosperous enterprises and thus the ROC could not be plotted. Considering the classification range of the AUC curve, good prediction accuracy is typical of the general agricultural model; fair accuracy of the model for small agricultural enterprises and Ch-index; poor accuracy for G-index.

An overlay of both measures, confusion matrix and AUC, indicates that the worst results were achieved by the Altman model, general Slovak model, and the model for medium-sized agricultural enterprises. These three models did not even reach the low required level and therefore it would be better to prefer some other models when modeling the financial stability of agricultural enterprises. The ROC curve of the best prediction model in the business environment of Slovak enterprises is presented in Figure 1.

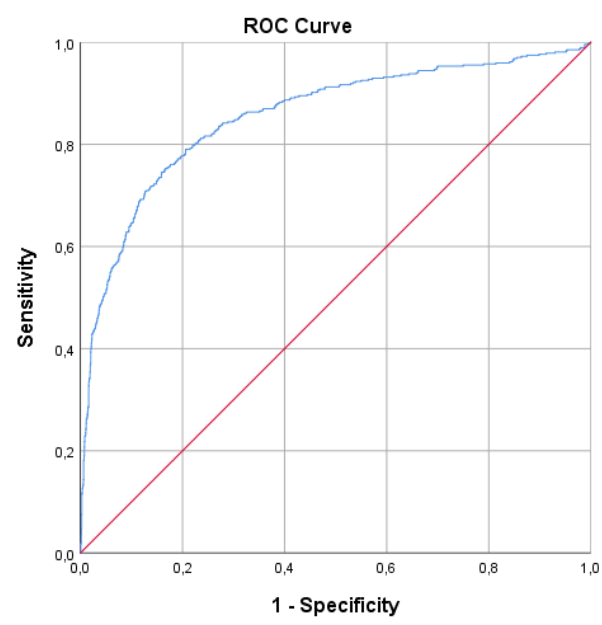

(a)

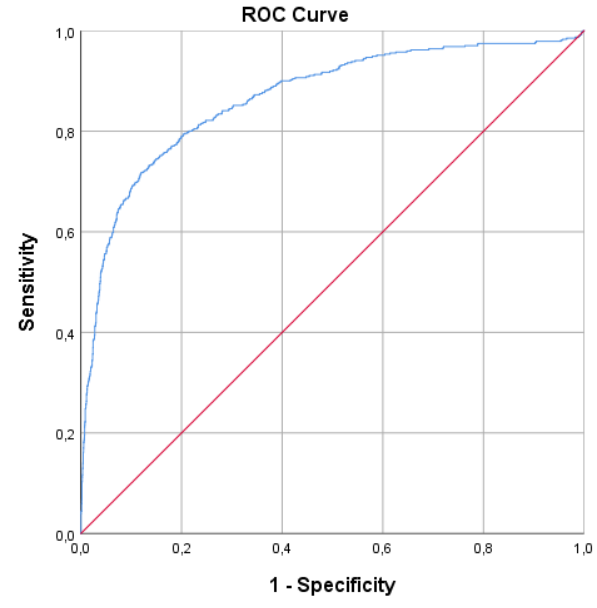

(b)

Figure 1. Cont. 


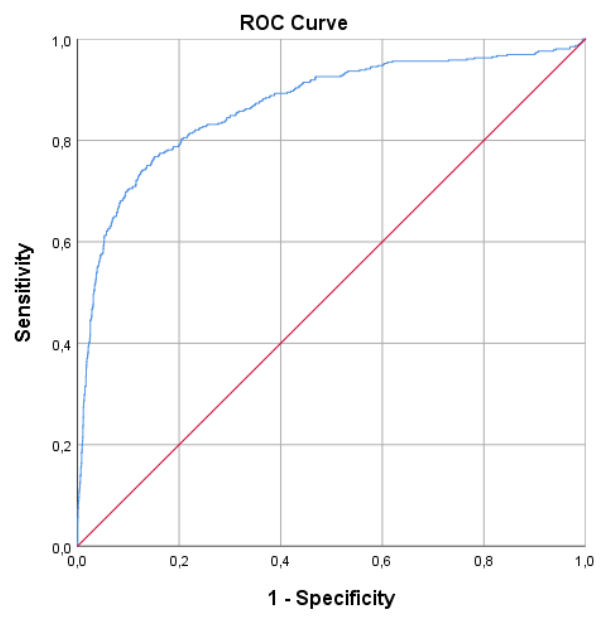

(c)

Figure 1. ROC curve of the general agricultural model of Slovak enterprises. (a) ROC curve in 2018;

(b) ROC curve in 2017; (c) ROC curve in 2016.

Summarizing the results in the context of the main aim of the paper, the verification of the predictive ability of the selected bankruptcy models reveals, that when modeling the future economic stability of agricultural enterprises, it is recommended to use general agricultural model (three-year average values of selected statistical methods assessing the predictive ability of the model are portrayed in Table 7).

Table 7. Total assessment of the general agricultural model of SR.

\begin{tabular}{ccccccc}
\hline Model & Total Accuracy & Sensitivity & Specificity & Type I Error & Type II Error & AUC \\
\hline $\begin{array}{l}\text { Agricultural } \\
\text { model of SR }\end{array}$ & $65.78 \%$ & $62.11 \%$ & $87.39 \%$ & $37.72 \%$ & $11.61 \%$ & 0.863 \\
\hline
\end{tabular}

Source: processed by authors.

This model captures $87.39 \%$ of all non-prosperous (financially unstable) agricultural enterprises in the database, thus, being able to predict the future development of a business entity and to recognize its financial stability in the upcoming period, may help minimize the potential risks of business partners. Moreover, low levels of error rates (type I and II) indicate, that incorrect decision about prosperity (non-prosperity) was made only in few cases, i.e., 11.61\% non-prosperous enterprises were identified as prosperous. The accuracy measured by the area under the ROC curve confirms the good predictive ability of the model achieving the average value of 0.863 .

The recognition of the most significant ways of financial stability modeling-the general agricultural model and model for large agricultural enterprises-reveals the importance of financial ratios used in the prediction model. The identification of the crucial financial ratios in a specific industry is a partial aim of the research on agricultural enterprises. The prediction model for large agricultural enterprises is based on five financial ratios, four of them are used as predictors also in the general model for agricultural enterprises of Slovakia. Both models with the highest prediction accuracy use net-income-to-equity ratio, current-liabilities-to-total-assets, current-assets-to-sales, and working-capital-to-sales as predictors of the future financial health of enterprises. Moreover, no other analyzed model uses the same combination of financial ratios when modeling the financial stability of agricultural entities. Net-income-to-equity ratio is an indicator of the managerial effectiveness at using equity financing to fund operation and grow the enterprise (Sumiyana et al. 2019; Harrower 2019). The inclusion of the current-liabilities-to-total-assets in the modeling of financial stability has a positive aspect, as this ratio is associated with insolvency, indicating a greater risk of financial failure achieving a higher value of the ratio (Al-Kassar and Soileau 2014). The current-asset-to-sales ratio reveals if 
an enterprise is facing a liquidity problem. As claimed by Karas and Srbova (2019) this ratio can vary by industry, is recommended to be used as a benchmark and tracked over time. From the group of all eight analyzed models, no other model uses this ratio as a predictor of financial stability. The working-capital-to-sales ratio shows the ability of the enterprise to pay its costs without the need to take on additional debt (Olah et al. 2019). Financial stable enterprises achieve higher values of this ratio, however, the descriptive statistics of the dataset of analyzed enterprises indicate that the average value of this ratio is negative. As corporate sales cannot be negative, it the issue of the working capital. Negative working capital does not necessarily show a problem. This can happen if the current liabilities exceed the level of current assets, however, the positive aspect of the negative working capital may be a consequence of the quick generation of cash.

The importance of the use of financial indicators was investigated by several authors. Virag (2004) explores financial ratios, which are most frequently used when modeling future financial situation of enterprises: cash flow to total liabilities, cash flow to non-current liabilities, earnings after taxes to total assets, total liabilities to total assets, net working capital to total assets, liquidity ratio, funds to short term liabilities, and net working capital to sales. Beaver et al. (2005) and Beaver et al. (2012) investigate the impact of dissimilarities in financial reporting and highlight the attributes of the predictive ability of financial ratios used in the bankruptcy prediction models. Bahiraie et al. (2011) present a list of 40 highly regarded financial ratios to predict the bankruptcy problems reflecting different aspects of corporate structure and performance, especially liquidity, turnover, operating structure and efficiency, capitalization, and profit ability. Andrés et al. (2012) consider a set of 22 financial ratios to assess the financial situation of a company. In their selection process, they considered previous research on the determinants of profitability and bankruptcy. Besides, other authors have included indicators of liquidity, indebtedness, asset turnover, efficiency and productivity, margin, growth, financing cost, and profitability indicators in their studies. Antonowicz (2014) analyzes the financial performance of an enterprise applying five chosen ratios, which are the most important financial indicators used in financial-economic analysis: general assets productivity ratio, profit/loss on sales to the average annual balance sheet total ratio, return on investment, gross asset productivity ratio, and return on assets. In addition, important implications for bankruptcy prediction research and practice, especially in terms of identifying the most important financial predictors, were unveiled in the research of Lukason and Laitinen (2019). Kovacova et al. (2019) unveil the dependence between explanatory variables used in the prediction models and a country of the origin. The research of the Visegrad group countries confirms that different financial ratios are used in these countries when modeling financial prosperity of enterprises. The group of indicators appropriate for Slovakia partly correspondents with our findings, stressing the importance of current-liabilities-to-total-assets, current-assets-to-sales, and working-capital-to-sales. The broader research of financial ratios in prediction models of transition economies (Kliestik et al. 2020) identified the most important financial predictors for specific clusters of countries. The predictors determined for Slovakia affirm the importance of the financial ratios used in the Slovak agricultural model with the highest prediction accuracy.

\section{Conclusions}

The financial situation of enterprises reflects their economic and financial stability. Financial analysis and continuous assessment of the financial situation may help identify the weaknesses of an enterprise and determine those financial factors that may have a significant effect on corporate bankruptcy in the future. The bankruptcy prediction models are the important tools of the financial analysis as their task is to forecast the future situation in advance and take adequate measures to prevent undesirable developments. The financial stability modeling can be realized using models which are based on various statistical methods. Previous studies have revealed that the best results in prediction are achieved if the models are applied in the same conditions as they were created. Thus, the main aim of the research was to investigate the relevance, prediction ability, and accuracy of the models (based on MDA method) being developed in Slovak environment, compare them, verify their 
predictive ability using divergent statistical methods, and identify crucial financial ratios used in the agricultural models.

The dataset of 3329 enterprises was applied to eight prediction models, seven of them developed in the same economic environment (in Slovakia) and the Altman's Z score to compare the results with the best known bankruptcy model. Measuring the prediction accuracy of these models by confusion matrix and ROC curve, it was found, that some of them achieve much better results compared to the others. The results reveal, that the Altman's model is absolutely inappropriate to be used to predict the future financial stability of Slovak models, showing low levels of all important measures. General Slovak model has a very low value of AUC (slightly over zero) and total accuracy and sensitivity do not even achieve 50\%. The model for medium-sized agricultural enterprises shows similar results, getting below average values of total accuracy, sensitivity, specificity, and AUC. The total predictive accuracy slightly exceeding $50 \%$ is typical of the model for small enterprises and $G$ index but with a high ratio of correctly identified non-prosperous enterprises. Moreover, the AUC in both cases shows fair classification ability of the model in each analyzed period. Despite the fact, that $\mathrm{Ch}$-index demonstrates good results quantifying both the total accuracy and AUC, the ability to identify the non-prosperous business entities is very low ( $11 \%$ on average). The best prediction accuracy is achieved by the model for large agricultural enterprises and the general model for Slovak agricultural companies their predictive ability highly outperforms other analyzed models and are suggested to be used to model the future economic stability of agricultural enterprises. The identification of the most significant models supports the idea of the exploration of the importance of financial ratios in the prediction model. The results depict that both models with highest prediction accuracy use net-income-to-equity ratio, current-liabilities-to-total-assets, current-assets-to-sales, and working-capital-to-sales as predictors of the future financial health of agricultural enterprises in Slovakia.

Thus it can be assumed that not only the sectoral financial data play an important role when calculating the discriminant coefficient, but also the financial ratios (predictors) are important. Provided that the relevant model is used to assess the financial stability of enterprises, the potential financial risks can be eliminated and properly managed which is beneficial not only for the enterprises, but also for their business partners.

It is evident that the research has some limitations considering the selection of measures used to assess and verify the predictive accuracy of the models, which may be a subject of further research. Another important issue for future investigation is the analysis of the capital structure of agricultural enterprises (delineated by Dombrovska and Shostak 2016), as it gets more difficult to achieve high-quality production and trading activities without debts. However, the research brings new scientific findings in the field of bankruptcy prediction of agricultural enterprises thanks to a robust analysis covering all models developed for this specific economic sector.

Author Contributions: Conceptualization, P.D. and K.V.; Methodology, K.V. and P.D.; Software, P.A..; Validation K.V., P.A., and J.J.; Formal analysis, P.A.; Investigation, P.D. and K.V..; Resources, J.J.; Writing-original draft preparation, J.J. and K.V.; Writing-review and editing, K.V. and P.D.; Visualization, P.A.; Supervision, P.D.; Project administration, J.J. All authors have read and agreed to the published version of the manuscript.

Funding: This research was financially supported by the Slovak Research and Development Agency-Grant No. APVV-14-0841: Comprehensive Prediction Model of the Financial Health of Slovak Companies and Vega 1/0121/20: Research of transfer pricing system as a tool to measure the performance of national and multinational companies in the context of earnings management in conditions of the Slovak Republic and V4 countries.

Conflicts of Interest: The authors declare no conflict of interest. The funders had no role in the design of the study; in the collection, analyses, or interpretation of data; in the writing of the manuscript, or in the decision to publish the results.

\section{References}

Alaka, Hafiz A., Lukumon O. Oyedele, Hakeem A. Owolabi, Vikas Kumar, Saheed O. Ajayi, Olugbenga O. Akinade, and Muhammad Bilal. 2018. Systematic review of bankruptcy prediction models: Towards a framework for tool selection. Expert Systems with Applications 94: 164-84. [CrossRef] 
Al-Kassar, Talal A., and Jares S. Soileau. 2014. Financial performance evaluation and bankruptcy prediction (failure). Arab Economic and Business Journal 9: 147-55. [CrossRef]

Altman, Edward I. 1968. Financial ratios, discriminant analysis and the prediction of corporate bankruptcy. Journal of Finance 23: 598-609. [CrossRef]

Altman, Edward I., Malgorzata Iwanicz-Drozdowska, Erkki K Laitinen, and Arto Suvas. 2014. Distressed Firm and Bankruptcy Prediction in an International Context: A Review and Empirical Analysis of Altman's Z-Score Model. SSRN Library. Available online: https://ssrn.com/abstract=2536340 (accessed on 25 February 2020).

Andrés, Javier, Manuel Landajo, and Pedro Lorca. 2012. Bankruptcy prediction models based on multinorm analysis? An alternative to accounting ratios. Knowledge-Based Systems 30: 67-77. [CrossRef]

Antonowicz, Pawel. 2014. The analysis of ranges of variability of selected ratios from a group of assets productivity ratios three years before the declaration of bankruptcy by companies in Poland. Business and Economic Horizons 10: 202-13. [CrossRef]

Bahiraie, Alireza, A. K. M. Azhar, and Noor Akma Ibrahim. 2011. A new dynamic geometric approach for empirical analysis of financial ratios and bankruptcy. Journal of Industrial and Management Optimization 7: 947-65. [CrossRef]

Barboza, Flavio, Herbet Kimura, and Edward I. Altman. 2017. Machine learning models and bankruptcy prediction. Expert Systems with Applications 83: 405-17. [CrossRef]

Barbuta-Misu, Nicoleta, and Mara Madaleno. 2020. Assessment of bankruptcy risk of large companies: European countries evolution analysis. Journal of Risk and Financial Management 13: 58. [CrossRef]

Beaver, Willaim H. 1966. Financial ratios as predictors of failure. Journal of Accounting Research 4: 71-111. [CrossRef]

Beaver, William H., Maureen F. McNichols, and Jung-Wu Rhie. 2005. Have financial statements become less informative? Evidence from the ability of financial ratios to predict bankruptcy. Review of Accounting Studies 10: 93-122. [CrossRef]

Beaver, William H., Maria Correira, and Maureen G. McNichols. 2012. Do differences in financial reporting attributes impair the predictive ability of financial ratios for bankruptcy? Review of Accounting Studies 17: 969-1010. [CrossRef]

Ben Jabeur, Sami, and Youssef Fahmi. 2018. Forecasting financial distress for French firms: A comparative study. Empirical Economics 54: 1-14. [CrossRef]

Binh, Pham Vo Ninh, Trung Do Thanh, and Duc Vo Hong. 2018. Financial distress and bankruptcy prediction: An appropriate model for listed firms in Vietnam. Economic Systems 42: 616-24.

Chrastinova, Zuzana. 1998. Methods of Assessment of Economic Solvency and Prediction of Financial Situation of Agricultural Enterprises. Bratislava: VUEPP.

Dadayan, Elena, Anna Storozheva, and Ekaterina Letyagina. 2020. Impact of economic risks on the financial stability of agricultural enterprises. Web of Conferences 161: 01065.

Delina, Radoslav, and Miroslava Packova. 2013. Prediction bankruptcy models validation in Slovak business environment. EEM Ekonomie and Management 16: 101-12.

Dinterman, Robert, Ani L. Katchova, and Michael J. Harris. 2018. Financial stress ad farm bankruptcies in U.S. agriculture. Agricultural Finance Review 78: 441-56. [CrossRef]

Dombrovska, Sofia Oleksiyivna, and Iryna Ivanina Shostak. 2016. The role and importance of the enterprise's borrowed capital. Economic Processes Management 2: 1-8.

Durica, Marek, Jaroslav Frnda, and Lucia Svabova. 2019. Decision tree based model of business failure prediction for Polish companies. Oeconomia Copernicana 10: 453-69. [CrossRef]

Eklund, Johan, Nadine Levratto, and Giovanni B. Ramello. 2020. Entrepreneurship and failure: two sides of the same coin? Small Business Economics 54: 373-82. [CrossRef]

Farooq, Umar, and Muhammed Ali Jibran Qamar. 2019. Predicting multistage financial distress: Reflections on sampling, feature and model selection criteria. Journal of Forecasting 38: 632-48. [CrossRef]

Garcia, Vicente, Ana I. Marques, and Salvador J. Sanchez. 2019. Exploring the synergetic effects of samples types in the performance of ensembles for credit risk and corporate bankruptcy prediction. Information Fusion 47: 88-101. [CrossRef]

Gulka, Martin. 2016. The prediction model of financial distress of enterprises operating in conditions of SR. Biatec 24: 5-10.

Gurcik, Lubos. 2002. G-index-The financial situation prognosis method of agricultural enterprises. Agricultural Economics 48: 373-8. 
Hajek, Petr. 2018. Prediciting corporate investment/non-investment grade by using interval-valued fuzzy rule-based systems-A cross-region analysis. Applied Soft Computing 62: 73-85. [CrossRef]

Harrower, Kathryn. 2019. Algorithmic decision-making in organizations: Network data mining, measuring and monitoring work performance, and managerial control. Psychological issues in Human Resource Management 7: $7-12$.

Harumova, Anna, and Marianna Janisova. 2014. Rating Slovak enterprises by scoring functions. Ekonomicky Casopis 62: 522-39.

Horvathova, Jarmila, and Martina Mokrisova. 2018. Risk of bankruptcy, its determinants and models. Risks 6: 117. [CrossRef]

Hosaka, Taddaki. 2019. Bankruptcy prediction using imaged financial ratios and convolutional neural networks. Expert Systems with Applications 13: 287-99. [CrossRef]

Hurtosova, Jana. 2009. Development of Rating Model as a Tool to Assess the Enterprise Credibility. Ph.D. thesis, University of Economics in Bratislava, Bratislava, Slovakia.

Inam, Fraz, Aneeq Inam, Muhammed Abbas Mian, Adnan Ahmed Sheik, and Hayat Muhammed Awan. 2019. Forecasting bankruptcy for organizational sustainability in Pakistan. Journal of Economic and Administrative Sciences 35: 19-38. [CrossRef]

Jiang, Zhi-Qiang, Gang-Jin Wang, Askery Canabarro, Boris Podobnik, Chi Xie, H. Eugene Stanley, and Wei-Xing Zhou. 2018. Short term prediction of extreme returns based on the recurrence interval analysis. Quantitative Finance 18: 353-70. [CrossRef]

Karas, Michal, and Pavla Srbova. 2019. Prediciting bankruptcy in construction business: Traditional model validation and formulation of a new model. Journal of International studies 12: 283-96. [CrossRef] [PubMed]

Klepac, Vaclav, and David Hampel. 2016. Prediction of bankruptcy with SVM classifier among retail business companies in EU. Acta Universitatis 64: 627-34.

Kliestik, Tomas, Jana Kliestikova, Maria Kovacova, Lucia Svabova, Katarina Valaskova, Marek Vochozka, and Judit Olah. 2018a. Prediction of Financial Health of Business Entities in Transition Economies. New York: Addleton Academic Publishers.

Kliestik, Tomas, Maria Misankova, Katarina Valaskova, and Lucia Svabova. 2018b. Bankruptcy prevention: New effort to reflect on legal and social changes. Science and Engineering Ethics 24: 791-803. [CrossRef] [PubMed]

Kliestik, Tomas, Katarina Valaskova, George Lazaroiu, Maria Kovacova, and Jaromir Vrbka. 2020. Remaining Financially Healthy and Competitive: The Role of Financial Predictors. Journal of Competitiveness 12: 74-92. [CrossRef]

Korol, Tomasz. 2019. Dynamic bankruptcy prediction models for European enterprises. Journal of Risk and Financial Management 12: 185. [CrossRef]

Kovacova, Maria, and Tomas Kliestik. 2017. Logit and Probit application for the prediction of bankruptcy in Slovak companies. Equilibrium-Quarterly Journal of Economics and Economic Policy 12: 775-91. [CrossRef]

Kovacova, Maria, Tomas Kliestik, Katarina Valaskova, Pavol Durana, and Zuzana Juhaszova. 2019. Systematic review of variables applied in bankruptcy prediction models of Visegrad group countries. Oeconomia Copernicana 10: 743-72. [CrossRef]

Krastev, Vladislav, Blagovesta Koyundzhiyska-Davidkova, and Irina Atanasova. 2019. The impact of corruption on the business in Bulgaria and Romania. International Conference Knowledge-Based Organization 25: 57-62. [CrossRef]

Krastev, Vladislav, Blagovesta Koyundzhiyska-Davidkova, and Nadezhda Petkova. 2019. Contemporary trends in the development of the anti-corruption legislation of Republic of Bulgaria. International Conference Knowledge-Based Organization 25: 141-46. [CrossRef]

Krastev, Vladislav, Blagovesta Koyundzhiyska-Davidkova, and Irina Atanasova. 2020. The impact of the corruption on the sustainable development of the businesses in South-West Bulgaria. SHS Web of Conferences 74: 06015. [CrossRef]

Le, Tuong, Mi Young Lee, Jun Ryeol Park, and Sung Wook Baik. 2018. Oversampling technique for bankruptcy prediction: Novel features from a transaction dataset. Symmetry 10: 79. [CrossRef]

Li, Leon, and Robert Faff. 2019. Predicting corporate bankruptcy: What matters? International Review of Economics and Finance 62: 1-19. [CrossRef] 
Ludbrook, Frances, Katarina Frajtova Michalikova, Zdenka Musova, and Peter Suler. 2019. Business models for sustainable innovation in industry 4.0: Smart manufacturing processes, digitalization of production systems, and data-driven decision making. Journal of Self-Governance and Management Economics 7: 21-26.

Lukason, Oliver, and Maria-del-Mar Camacho-Minano. 2019. Bankruptcy risk, its financial determinants and reporting delays: Do managers have anything to hide? Risks 7: 77. [CrossRef]

Lukason, Oliver, and Ekrri K. Laitinen. 2019. Firm failure processes and components of failure risk: An analysis of European bankrupt firms. Journal of Business Research 98: 380-90. [CrossRef]

Mahtani, Umesh S., and Chandra Prakash Garg. 2018. An analysis of key factors of financial distress in airline companies in India using fuzzy AHP framework. Transportation Research Part A: Policy and Practice 117: 87-102. [CrossRef]

Mihalovic, Matus. 2016. Performance comparison of multiple discriminant analysis and logit models in bankruptcy prediction. Economics \& Sociology 9: 101-18.

Naidu, Pranav, and K. Govinda. 2018. Bankruptcy prediction using neural networks. Paper presented at the 2nd International Conference on Inventive Systems and Control, Coimbatora, India, January 19-20.

Olah, Judit, Ardhi Hidayat Yusmat, Domician Mate, Adam Novotny, Jozsef Popp, Zoltan Lakner, and Sandor Kovacs. 2019. A trust approach to the financial performance of information and communications technology enterprises. Polish Journal of Management Studies 20: 332-43.

Patrick, Kevin, Ryan Kuhns, and Allison Borchers. 2016. Recent trends in U.S. farm income, wealth, and financial health. Choices The Magazine of Food Farm and Resource Issues. 31: 1-8. [CrossRef]

Popescu, Madalina Ecaterina, and Dragota Victor. 2018. What do post-communist countries have in common when predicting financial distress? Prague Economic Papers 27: 637-53. [CrossRef]

Prusak, Blazej. 2019. Review of research into enterprise bankruptcy prediction in selected central and European countries. International Journal of Financial Studies 6: 60. [CrossRef]

Rahman, Ashiqur, Jaroslav Belas, Tomas Kliestik, and Ladislav Tyll. 2017. Collateral requirements for SME loans: Empirical evidence from the Visegrad countries. Journal of Business and Management 18: 650-75. [CrossRef]

Sautner, Zacharias, and Vladimir Vladimirov. 2018. Indirect costs of financial distress and bankruptcy law: Evidence from trade credit and sales. Review of Finance 22: 1667-704. [CrossRef]

Sedlacek, Jaroslav. 2010. The methods of valuation in agricultural accounting. Agricultural Economics 56: 59-66.

Siekelova Anna, Tomas Kliestik, and Peter Adamko. 2018. Predictive ability of chosen bankruptcy models: A case study of Slovak Republic. Economics and Culture 15: 105-14. [CrossRef]

Stefko, Robert, Sylvia Jencova, Petra Vasanicova, and Eva Litavcova. 2019. An evaluation of financial health in the electrical engineering industry. Journal of Competitiveness 11: 144-60. [CrossRef]

Stehel, Vojtech, Jakub Horak, and Marek Vochozka. 2019. Prediction of institutional sector development and analysis of enterprises active in agriculture. E + M Ekonomie a Management 22: 103-18. [CrossRef]

Sumiyana, Sumiyana, Sari Atmini, and Slamet Sugiri. 2019. Predictive power of aggregate corporate earnings and their components for future GDP growth: An international comparison. Economics and Sociology 12: 125-42. [CrossRef]

Svabova, Lucia, and Marek Durica. 2019. Being an outlier: A company non-prosperity sign? Equilibrium-Quarterly Journal of Economics and Economic Policy 14: 359-75. [CrossRef]

Virag, Miklos. 2004. Financial Analysis, Bankruptcy Prediction. Budapest: Szinkron Press.

Vrbka, Jaromir, EWlvira Nica, and Ivana Podhorska. 2019. The application of Kohonen networks for identification of leaders in the trade sector in Czechia. Equilibrium- Quarterly Journal of Economics and Economic Policy 14: 739-61. [CrossRef]

Waqas, Hamid, and Rohani Md-Rus. 2018. Predicting financial distress: Applicability of O-score model for Pakistani firms. Business and Economic Horizons 14: 389-401. [CrossRef]

Zoricak, Martin, Peter Gnip, Peter Drotar, and Vladimir Gazda. 2020. Bankruptcy prediction for small-and medium-sized companies using severely imbalanced datasets. Economic Modeling 84: 165-76. [CrossRef]

(C) 2020 by the authors. Licensee MDPI, Basel, Switzerland. This article is an open access article distributed under the terms and conditions of the Creative Commons Attribution (CC BY) license (http://creativecommons.org/licenses/by/4.0/). 